\title{
Studi Perubahan Garis Pantai Berdasarkan Interpretasi Citra Satelit Landsat dan Perhitungan Rasio Lahan di Wilayah Pesisir Indramayu Jawa Barat
}

\author{
Thonas Indra Maryanto ${ }^{1}$, Wiwin Windupranata ${ }^{2}$, Samsul Bachri ${ }^{2}$ \\ ${ }^{1}$ Jurusan Teknik Geodesi, Fakultas Teknik Sipil dan Perencanaan, ITENAS, \\ Bandung \\ 2 Jurusan Teknik Geodesi dan Geomatika, Fakultas Ilmu dan Teknologi \\ Kebumian, ITB- Bandung \\ Email: thonas.indra@gmail.com
}

\begin{abstract}
ABSTRAK
Wilayah pesisir sebagai kawasan peralihan yang menghubungkan ekosistem darat dan ekosistem laut, sangat rentan terhadap kerusakan dan perubahan yang diakibatkan oleh berbagai aktifitas manusia di darat maupun di laut. Kabupaten Indramayu merupakan salah satu wilayah di Pesisir Utara Jawa Barat yang mengalami kerusakan paling parah diantara seluruh kabupaten di wilayah pesisir Utara Jawa Barat serta memiliki penggunaan lahan pesisir yang cukup lengkap mulai dari pemukiman, persawahan, tambak, dan industri (PLTU dan MIGAS)..Besarnya perubahan garis pantai yang meliputi abrasi dan sedimentasi diturunkan dari data citra satelit Landsat wilayah pesisir Kabupaten Indramayu tahun 1994-2009 dengan metode komposit RGB 4, 5, 7 dan Metode AGSO kemudian dilakukan proses digitasi.. Luas abrasi di 11 Kecamatan Pesisir Indramayu dari tahun 1994 - 2009 sebesar 3900,41 Ha dengan laju abrasi rata-rata sebesar 23,64 Hal tahun dan Luas sedimentasi sebesar 650,29 Ha dengan laju sedimentasi rata-rata sebesar 4,81 Ha/tahun. Hasil perhitungan regresi terhadap rasio lahan penduduk untuk tahun 2015 sebesar 0,07 Hal jiwa dan menurun pada tahun 2025 menjadi 0,05 Ha/jiwa .Rasio lahan petani untuk tahun 2015 sebesar 0,66 Ha/petani dan menurun menjadi 0,55 Ha/petani di tahun 2025.
\end{abstract}

Kata Kunci : Pesisir indramayu, citra satelit, abrasi dan sedimentasi, Rasio lahan

\begin{abstract}
Coastal areas as a transitional region connecting the land ecosystems and marine ecosystems, are vulnerable to damage and changes caused by various human activities on land and at sea. Indramayu regency is one of the areas in the North Coast of West Java is the most severely damaged among all districts in the northern coast of West Java and has a coastal land use complete enough from residential areas, wet rice fields, ponds, and industrial (power plant and Gas). The number of change in coastal line include erosion and sedimentation derived from Landsat satellite image data coastal areas of Indramayu district in 1994-2009 with the composite method RGB 4, 5, 7 and methods AGSO then do the digitization process. The extent of abrasion in 11 districts of the coastal Indramayu from 1994 - 2009 are 3900.41 hectares with average abrasion rate of 23.64 ha / year and sedimentation area of 650.29 hectares with an average sedimentation rate of 4.81 ha / year. Results of regression calculations to land ratio for the 2015 population of 0.07 ha / life and decreased in 2025 to 0.05 hectares /life. Rasio farmers' fields for 2015 of 0.66 ha / farmer and decreased to 0.55 Ha / farmers in 2025.
\end{abstract}

Keywords: Coastal area of indramayu, satellite imagery, erosion and sedimentation, land Ratio 


\section{PENDAHULUAN}

Kabupaten Indramayu, di Provinsi Jawa Barat mempunyai wilayah yang berada di Pantai Utara Jawa Barat. Kabupaten Indramayu memiliki garis pantai sepanjang $114 \mathrm{~km}$ dan memiliki 3 pulau kecil yaitu, Pulau Biawak, Pulau Gosong dan Pulau Cendikian. Wilayah pesisir Kabupaten Indramayu memiliki potensi sumber daya non-hayati, seperti tambang dan mineral serta keanekaragaman sumberdaya hayati yang sangat tinggi seperti estuaria, mangrove, terumbu karang, padang lamun dan pantai berpasir [3]. Kabupaten Indramayu merupakan salah satu wilayah di Pantai Utara Jawa Barat yang mengalami kerusakan paling parah diantara seluruh kabupaten di wilayah pesisir Utara Jawa Barat serta memiliki variasi penggunaan lahan pesisir yang cukup lengkap mulai dari pemukiman, persawahan, tambak, dan industri (PLTU dan MIGAS). Dari seluruh garis pantai sepanjang $114 \mathrm{~km}$, hampir 90 persennya telah mengalami abrasi dan telah menenggelamkan sedikitnya 6.145 Ha lahan di wilayah pesisirnya (Gambar 1). Kerusakan yang terjadi di wilayah pesisir Indramayu tentunya akan berdampak terhadap kegiatan perekonomian penduduk yang melakukan aktivitasnya di wilayah pesisir ini [5].

Kerusakan atau hilangnya lahan ini tentu menimbulkan kerugian ekonomi yang tidak sedikit. Perubahan garis pantai berpengaruh pada entitas lahan (luas, fungsi, produktivitas) serta entitas penduduknya (jumlah, struktur dan pertumbuhannya). Daya dukung dan kapasitas fungsi wilayah perlu dikelola oleh pemerintah agar manfaatnya mampu mengimbangi kebutuhan penduduk yang selalu bertambah. Manfaat ruang wilayah terhadap penduduk adalah sebagai media untuk melangsungkan kehidupannya (tempat tinggal, tempat kegiatan usaha, sumber produksi kebutuhan pangan dan sebaginya). Berkaitan dengan hal tersebut, maka dilakukan penelitian perubahan garis pantai di wilayah pesisir pada 11 kecamatan pesisir kabupaten Indramayu dengan menggunakan citra satelit Landsat dan perhitungan rasio lahan untuk tahun 2015 dan 2025.
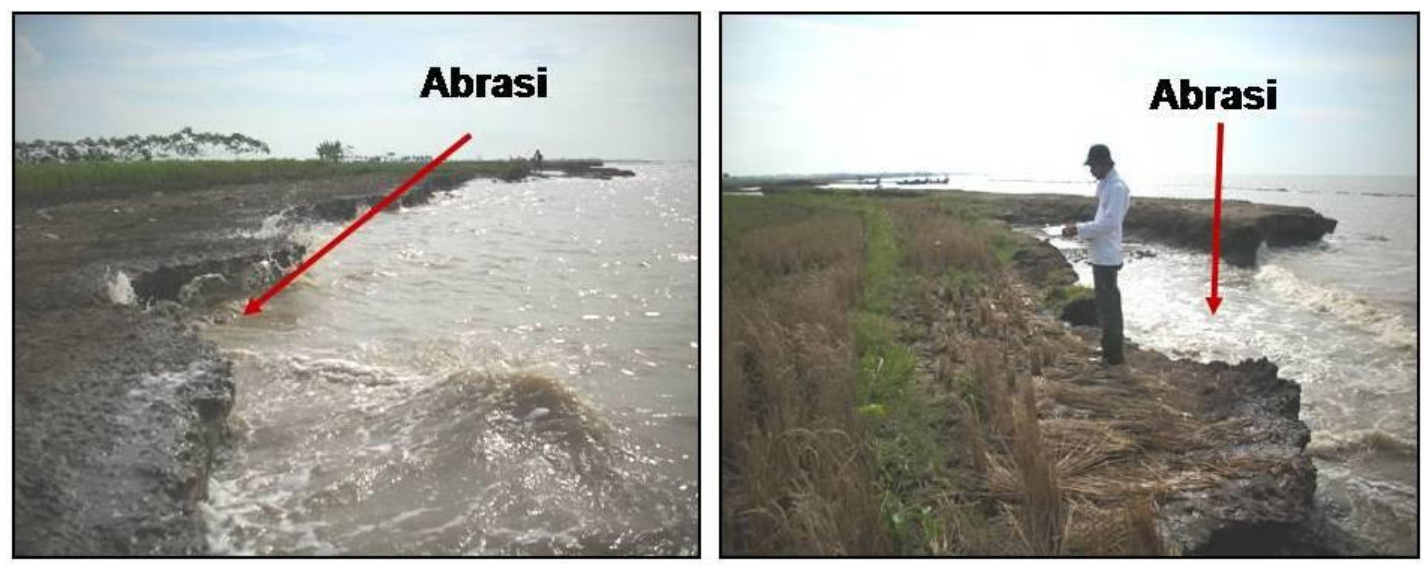

Gambar 1. Abrasi di Wilayah Pesisir Indramayu

\section{METODOLOGI}

\subsection{Lokasi Penelitian}

Menurut Dinas Perikanan Provinsi Jawa Barat [3], Kabupaten Indramayu secara geografis berada pada $107^{\circ} 52^{\prime}-108^{\circ} 36^{\prime}$ Bujur Timur dan $6^{\circ} 15^{\prime}-6^{\circ} 40$ Lintang Selatan. Berdasarkan topografinya sebagian besar merupakan dataran atau area landai dengan kemiringan tanahnya rata-rata $0-2 \%$. Secara administratif Kabupaten Indramayu berbatasan dengan:

- Sebelah Utara, berbatasan dengan Laut Jawa,

- Sebelah Selatan, berbatasan dengan Kabupaten Majalengka, Sumedang dan Cirebon,

- Sebelah Barat, berbatasan dengan Kabupaten Subang,

- Sebelah Timur,berbatasan dengan Laut Jawa dan Kabupaten Cirebon.

Daerah penelitian adalah wilayah pesisir Kabupaten Indramayu yang terdiri dari 11 Kecamatan Pesisir (Gambar 2) 


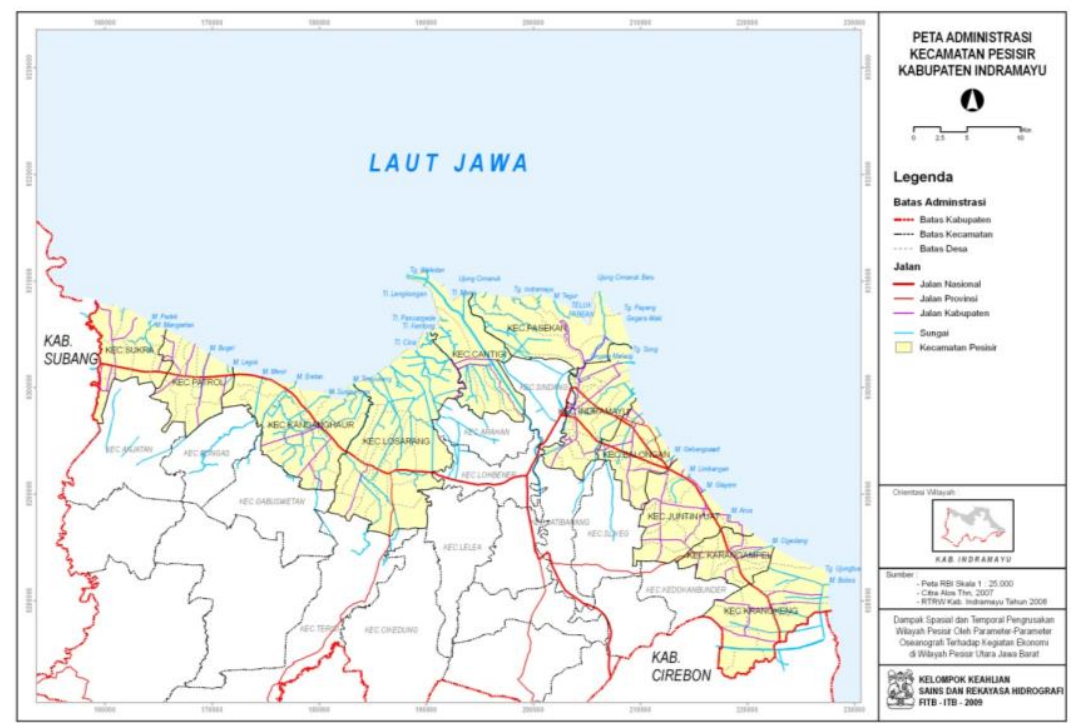

Gambar 2. Peta 11 Kecamatan Pesisir Kabupaten Indramayu [2]

Tabel 1. Nama dan Luas Wilayah Kecamatan Pesisir Kabupaten Indramayu [3]

\begin{tabular}{|c|c|c|c|}
\hline No & Kecamatan & Luas $\left[\mathbf{k m}^{2}\right]$ & Panjang Garis Pantai [Km] \\
\hline 1 & Krangkeng & 73.953 & 6 \\
\hline 2 & Karangampel & 62.513 & 1 \\
\hline 3 & Juntinyuat & 53.610 & 11 \\
\hline 4 & Balongan & 36.533 & 6 \\
\hline 5 & Indramayu & 53.986 & 6 \\
\hline 6 & Cantigi & 58.624 & 16 \\
\hline 7 & Pasekan & 68.709 & 31 \\
\hline 8 & Losarang & 137.874 & 12 \\
\hline 9 & Kandanghaur & 85.822 & 13 \\
\hline 10 & Sukra & 44.883 & 5 \\
\hline & Patrol & 43.330 & 8 \\
\hline & Total & 719.842 & 114 \\
\hline
\end{tabular}

\subsection{Data}

Data yang digunakan dalam penelitian ini terbagi menjadi data primer dan data sekunder. Data primer berupa data survey keadaan fisik lingkungan pesisir indramayu dan wawancara dengan penduduk wilayah studi. Data sekunder berupa data citra satelit Landsat dan dokumen sosial ekonomi yang berasal dari pemerintah daerah setempat.

Tabel 2. Data dan Sumber Data Penelitian

\begin{tabular}{clll}
\hline No & \multicolumn{1}{c}{ Data } & \multicolumn{1}{c}{ Akusisi Tahun } & \multicolumn{1}{c}{ Sumber } \\
\hline 1 & Citra Landsat TM & 14 Agustus 1994 & LAPAN \\
\hline 2 & Citra Landsat7 ETM+ & 22 Juni 2001 & LAPAN \\
\hline 3 & Citra Landsat7 ETM+ & 29 April 2003 & USGS GLOVIS \\
\hline 4 & Citra Landsat7 ETM+ & 20 Agustus 2005 & USGS GLOVIS \\
\hline 5 & Citra Landsat7 ETM+ & 9 Juli 2007 & USGS GLOVIS \\
\hline 6 & Citra Landsat7 ETM+ & 18 Oktober 2009 & USGS GLOVIS \\
\hline 7 & Peta RBI & 1992 & BAKOSURTANAL \\
\hline 8 & Dokumen Sosial & $2007-2010$ & $\begin{array}{l}\text { BPS Indramayu } \\
\text { dan Survey Lapangan }\end{array}$ \\
\hline 9 & Ekonomi & & USGS \\
\hline
\end{tabular}




\subsection{Metodologi Penelitian}

Perhitungan luas abrasi dan sedimentasi didasarkan pada interpretasi citra satelit Landsat. Citra Satelit Landsat 7 pada periode tahun 2003 keatas (kecuali Landsat 8) mengalami gangguan sensor, yang berakibat data citra terdapat gap atau gangguan berupa garis-garis mendatar yang sering disebut kondisi SLC OFF. Sehingga perlu dilakukan perbaikan atau pengisian pada bagian citra yang terdapat gap tersebut. Setelah perbaikan citra dilakukan, tahap selanjutnya adalah koreksi geometrik yang tujuannya agar citra tersebut bergeoreferensi (memiliki koordinat). Citra yang sudah bergeoreferensi ini kemudian dilakukan masking citra, atau pemisahan antara daratan dan perairan (laut). Proses pemisahan daratan dan perairan (laut) ini sangat penting karena berfungsi untuk mengidentifikasi garis pantai yang akan diteliti perubahannya. Metode yang dipakai untuk proses masking citra adalah metode komposit Red Green Blue (RGB) 457 dan metode AGSO. Komposit warna RGB adalah penggabungan tiga band atau tiga informasi yang berbeda dalam tiga warna utama yaitu Merah (redR), Hijau (green-G) dan Biru (blue- B). Nilai skala abu-abu yang terdapat pada masing-masing band digunakan untuk membentuk himpunan atau gabungan kecerahan warna merah, hijau dan biru. Penggabungan citra dengan metode RGB sangat umum digunakan untuk berbagai keperluan diantaranya adalah untuk mempermudah analisis visual dari pemisahan daratan dan perairan. Metode AGSO merupakan metode pemetaan perairan dangkal dari citra (shalow water image mapping) yang dikembangkan oleh Australian Geological Surveys Organization (AGSO). Formulasi AGSO ini merupakan rumusan matematis yang digunakan dalam menjelaskan hubungan antara sinyal gelombang elektromagnet, medium propagasi, partikel dalam air, serta efek kedalaman suatu perairan. Berdasarkan karakteristik spektralnya, obyek air memiliki persentase reflektansi yang tinggi pada band antara 0,3-0,7 $\mu \mathrm{m}$. Band dengan panjang gelombang demikian merupakan band cahaya tampak (visible light), maka pada sensor Landsat TM, band ini (Band 1, 2 dan 3) mampu melakukan penetrasi ke permukaan suatu dasar perairan. Radiasi yang muncul dari air pada suatu perairan dangkal adalah suatu kombinasi dari: pantulan dari material substrat dasar perairan, kedalaman air, penyerapan dan hamburan oleh molekul air, partikel-partikel, dan material-tersuspensi (organik-anorganik) dan pengaruh dari efek atmosfer sebagai medium perambatan gelombang elektromagnet.

Rumus umum yang digunakan pada metode AGSO adalah Persamaan 1 sebagai berikut [5]:

$$
\text { If } B_{5}<D \text { and } B_{1}>0 \text { then }\left(\log \left(B_{1}-m_{1}\right) / K_{1}\right)+\left(\log \left(B_{2}-m_{2}\right) / K_{2}\right)+\left(\log \left(B_{3}-m_{3}\right) / K_{3}\right) \text { else null }
$$

dimana :

$\begin{array}{ll}B_{1} & : \text { band } 1, \\ B_{3} & : \text { bBand } 3, \\ D & : \text { nilai BV darat terendah untuk band } 5, \\ m_{2} & : \text { nilai BV terendah band } 2, \\ B_{2} & : \text { band } 2, \\ B_{5} & : \text { band } 5, \\ m & : \text { nilai BV terendah band } 1, \\ m_{3} & : \text { nilai BV terendah band 3, } \\ K_{1}, K_{2}, K_{3} & : \text { koefisien pengurangan cahaya pada band 1, 2,3 }\end{array}$

Setelah semua citra diproses masking, kemudian dilakukan proses digitasi citra. Digitasi adalah proses penentuan objek atau fenomena alam lainnya dipermukaan bumi dengan cara interpretasi secara visual. Proses digitasi adalah suatu pekerjaan yang dilakukan untuk mengkonversi data bentuk raster menjadi bentuk vektor. Proses ini harus dilakukan secara teliti dan cermat. Perhitungan luas abrasi diperoleh dari proses tumpang susun (overlay) citra yang telah didigitasi. Perhitungan rasio lahan didasarkan pada perbandingan antara luas wilayah dengan jumlah penduduk yang menempati wilayah tersebut. Sebagai contoh, untuk melihat keseimbangan produksi dan konsumsi, rasio lahan dihitung dari luas lahan dibagi jumlah penduduk. Untuk melihat besarnya rasio lahan di sektor pertanian, rasio lahan dihitung dari luas lahan dibagi jumlah petani. Dari keterangan tersebut secara model matematik Perhitungan rasio lahan dapat dituliskan seperti dalam Persamaan (2) [4]. 


$$
R L=\frac{L}{P}
$$

dimana:

$L=$ luas lahan,

$P=$ jumlah penduduk.

Nilai rasio lahan yang diperoleh dari bila dikorelasikan dengan data laju abrasi, maka nilai rasio lahan akan semakin menurun sebagai akibat dari variabel-variabel [4] yaitu:

1. Variabel laju pertumbuhan penduduk $\left(L_{p}\right)$.

2. Variabel laju abrasi pertahun $\left(L_{a}\right)$ dan laju sedimentasi per tahun $\left(L_{s}\right)$.

3. Variabel alih fungsi lahan seperti permukiman, infrastuktur dan lain-lain $\left(A_{f}\right)$, karena rasio lahan dihitung terhadap semua fungsi lahan, maka tidak terdapat pengaruh alih fungsi lahan $\left(A_{f}\right)$ terhadap rasio lahan.

Sehingga model prediksi rasio lahan-petani (RL) terhadap luas lahan pangan eksiting $\left(L_{e}\right)$ merupakan fungsi dari $L_{p}, P_{d}, A_{b}$ dan $A_{f}$ atau dalam bentuk fungsi matematik diperlihatkan pada Persamaan (3) [4].

$$
R L_{n}=\frac{\left[L-\left(L_{a} * n\right)+\left(L_{s} * n\right)\right]}{P_{0}+\left(1+P_{d}\right)^{t}}
$$

dimana:

$L=$ luas lahan pada kondisi awal,

$L_{a}=$ laju abrasi,

$L_{s}=$ laju sedimentasi,

$n=$ selisih tahun dengan kondisi awal,

$A_{f}=$ laju alih fungsi lahan,

$P_{0}=$ jumlah penduduk atau jumlah petani,

$t=$ tahun prediksi dari 0 ke $t$,

$P_{d}=$ pertumbuhan penduduk, [\%].

Perhitungan prediksi jumlah penduduk untuk tahun 2015 dan 2025 menggunakan data eksisting pertumbuhan penduduk kecamatan pesisir Kabupaten Indramayu tahun 2007 yang bersumber dari BPS Kabupaten Indramayu.

Secara skematis metodologi penelitian dapat dilihat pada Gambar 3 berikut ini. 
Thonas Indra Maryanto, Wiwin Windupranata, Samsul Bachri

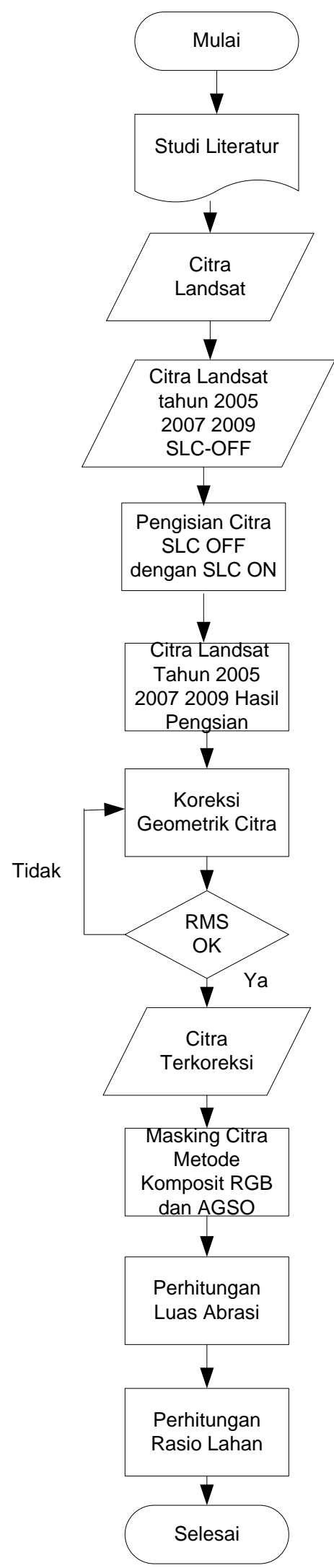

Gambar 3. Diagram Alir Penelitian

Rekayasa Hijau - 28 


\section{HASIL DAN PEMBAHASAN}

\subsection{Hasil Pengolahan Citra}

Hasil pengolahan citra untuk penentuan batas darat dan air dengan metode komposit Red Green Blue (RGB) untuk band 4, 5, 7 diperlihatkan pada Gambar 4, sedangkan penentuan batas darat dan air dengan metode AGSO diperlihatkan pada Gambar 5.

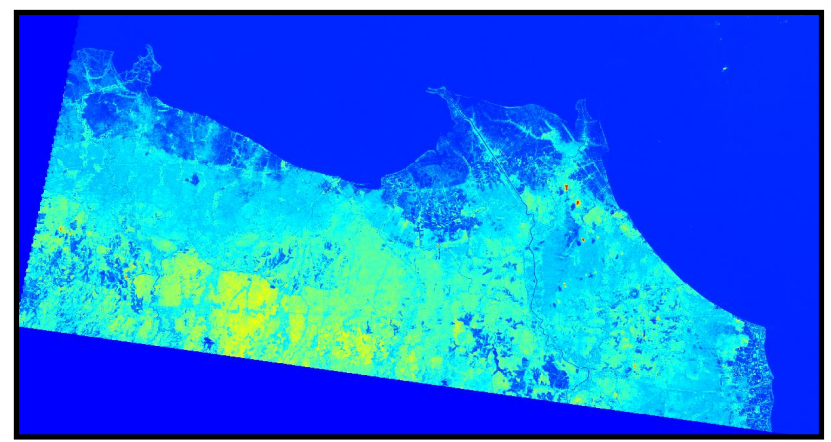

Gambar 4. Citra Landsat Komposit Band 4, 5, 7

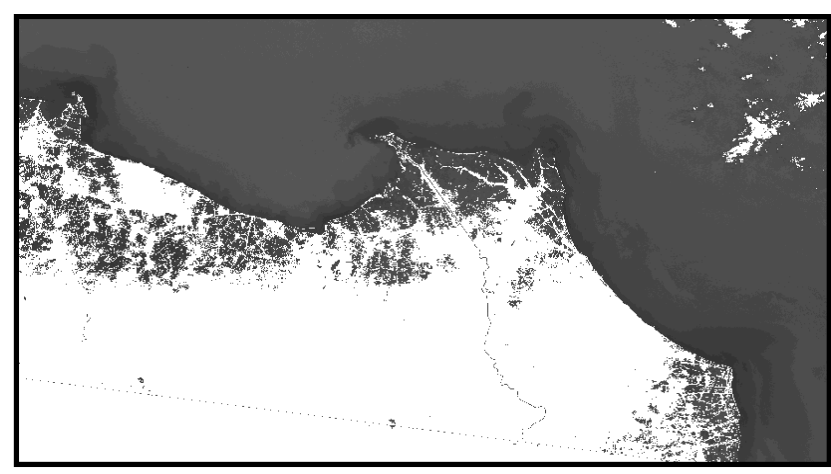

Gambar 5. Citra Landsat Metode AGSO

Secara visual citra baru hasil metode komposit RGB Band 4, 5, 7 memberikan kekontrasan yang terjelas antara darat dan air dibandingkan dengan band lainnya. Hal ini disebabkan Band 4, 5, dan 7 memiliki reflektansi yang rendah terhadap air dan reflektansi yang tinggi terhadap darat. Sehingga , kombinasi dari tiap band ini dapat memberikan hasil yang baik dalam membedakan batas yang jelas antara darat dan air yang berguna dalam menentukan kedudukan garis pantai. Metode AGSO juga memberikan kekontrasan yang jelas antara darat dan air, dimana obyek berupa daratan berwarna putih karena daratan mempunyai reflektansi yang tinggi dan obyek air berwarna hitam, karena perairan mempunyai reflektansi yang rendah Setelah pemilihan band citra dan metode AGSO dilakukan, tahap selanjutnya adalah proses digitasi dan tumpang susun (overlay) citra mulai dari tahun 1994, 2001, 2003, 2005, 2007 dan 2009. Proses digitasi adalah pekerjaan yang dilakukan untuk mengkonversi data bentuk raster menjadi bentuk vektor. Digitasi dari setiap periode tahun citra Landsat yang digunakan memberikan hasil yang sesuai, yaitu masing-masing citra saling bertumpang susun, hal ini dikarenakan sebelum proses digitasi berlangsung, data citra telah memiliki sistem proyeksi dan sistem koordinat yang sama dengan referensi yang digunakan. Setelah citra ditumpang susun, perhitungan perubahan garis pantai dilakukan, yaitu dengan cara melihat hasil digitasi citra. Citra tahun 1994 sebagai dasar patokan untuk menentukan kejadian abrasi dan sedimentasi. Garis pantai yang maju dari tahun 1994 maka diinterpretasikan sebagai sedimentasi, sedangkan garis pantai yang mundur diinterpretasikan sebagai abrasi. Setelah teridentifikasi abrasi dan sedimentasi, kemudian dilakukan perhitungan dengan software Arcview untuk menghitung luas abrasi dan sedimentasi tersebut (dalam satuan hektar). Data citra hasil dari digitasi dan overlay diperlihatkan pada Gambar 6 dan Gambar 7. Sedangkan contoh peta abrasi dan sedimentasi diperlihatkan pada Gambar 8. 


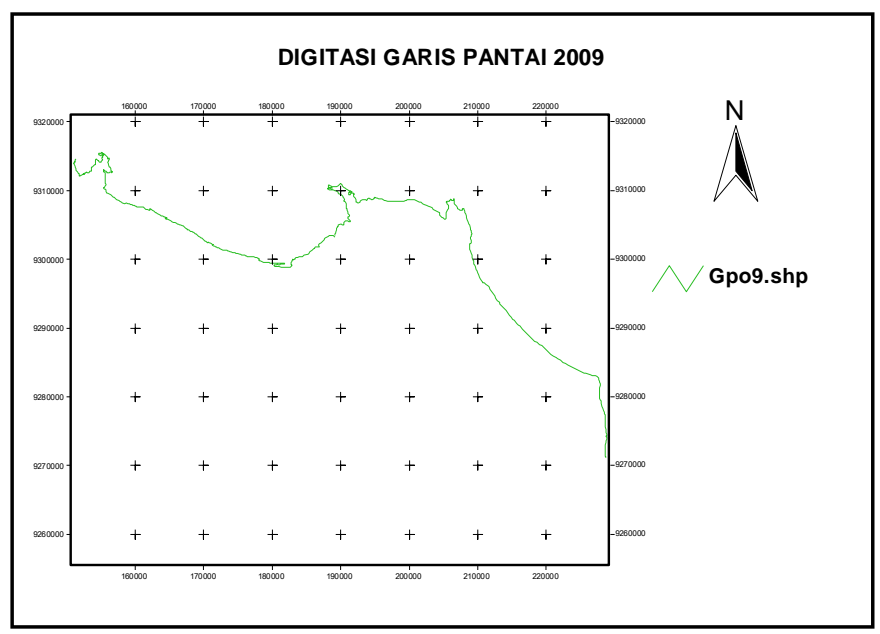

Gambar 6. Contoh Peta Digitasi Citra Tahun 2009

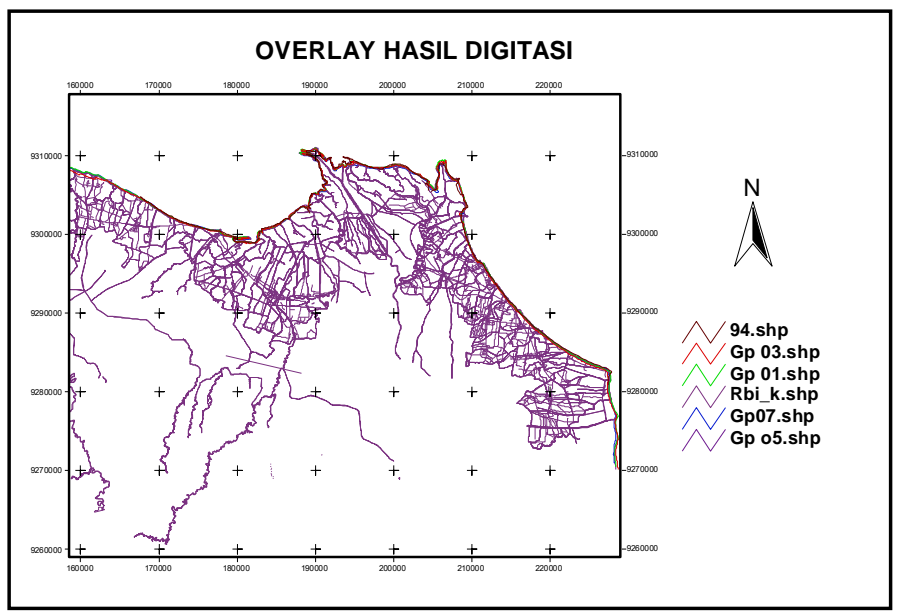

Gambar 7. Peta Tumpang susun (overlay) citra tahun 1994, 2001, 2003, 2005, 2007 dan 2009

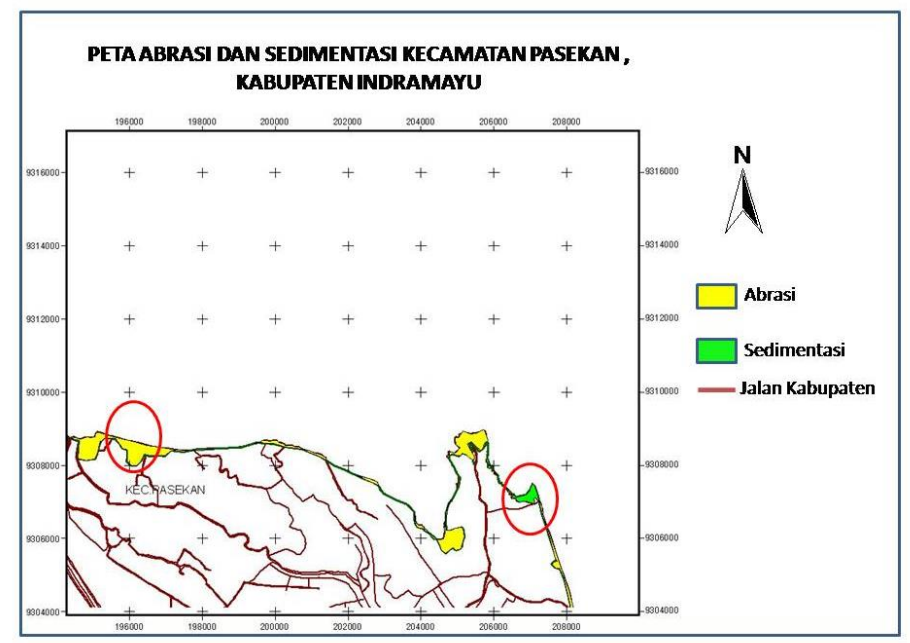

Gambar 8. Contoh peta abrasi dan sedimentasi, Kecamatan Pasekan

\subsection{Hasil Perhitungan Abrasi dan Sedimentasi}

Tumpang susun citra dengan periode tahun yang berbeda memberikan visualisasi mengenai kejadian abrasi di 11 kecamatan pesisir Indramayu. Garis pantai yang mundur (berkurang) dari tahun sebelumnya dikatakan mengalami abrasi sedangkan yang maju dari tahun sebelumnya dikatakan sedimentasi. Luasan abrasi dan sedimentasi masing-masing kecamatan berbeda beda. Proses abrasi dan sedimentasi yang terjadi 11 kecamatan pesisir Indramayu dipengaruhi oleh karakteristik 
oseanografi dan sedimen di daerah tersebut. Semakin kuat energi yang dilepaskan oleh gaya-gaya yang ada di laut seperti gelombang, pasut dan arus semakin besar, maka semakin besar pula proses perubahan garis pantai. Dari sisi resistensi garis pantai, semakin besar ukuran butir sedimen (untuk sedimen yang kohesif), maka semakin kuat garis pantai tersebut menahan erosi. Sedimentasi biasanya terjadi di daerah muara sungai dan pasokan sedimen dari sungai tersebut akan didistribusikan sesuai dengan arah dan kekuatan pasut, arus serta gelombang. Selain faktor oseanografi, faktor manusia juga berpengaruh terhadap peristiwa abrasi dan sedmentasi, sebagia contoh adalah perubahan tata guna lahan yang semula hutan mangrove dirubah menjadi pertambakan atau persawahan.

Pada Tabel 3 dapat dilihat bahwa periode tahun 1994 - 2009 luas abrasi terbesar terjadi di Kecamatan Sukra dengan luas abrasi mencapai 742,16 Ha dengan laju abrasi 49,48 Ha/tahun, sedangkan untuk sedimentasi, luas sedimentasi terbesar terjadi di Kecamatan Cantigi sebesar 219 Ha dengan laju sedimentasi $14,60 \mathrm{Ha} /$ tahun.

Tabel 3. Hasil Perhitungan Luas dan Laju Abrasi-Sedmentasi

\begin{tabular}{|c|c|c|c|c|c|c|}
\hline \multirow[t]{2}{*}{ No } & \multirow[t]{2}{*}{ Kecamatan } & \multirow{2}{*}{$\begin{array}{c}\text { Luas } \\
\text { Wilayah } \\
\text { [Ha] }\end{array}$} & \multicolumn{2}{|c|}{$\begin{array}{c}\text { Perubahan Garis Pantai } \\
(1994-2009)\end{array}$} & \multicolumn{2}{|c|}{$\begin{array}{l}\text { Laju Perubahan Garis } \\
\text { Pantai (1994-2009) }\end{array}$} \\
\hline & & & $\begin{array}{c}\text { Abrasi } \\
{[\mathrm{Ha}]}\end{array}$ & $\begin{array}{c}\text { Sedimentasi } \\
{[\mathrm{Ha}]}\end{array}$ & $\begin{array}{c}\text { Abrasi } \\
{[\mathrm{Ha} / \mathrm{Th}]}\end{array}$ & $\begin{array}{c}\text { Sedimentasi } \\
{[\mathrm{Ha} / \mathrm{Th}]}\end{array}$ \\
\hline 1 & Krangkeng & $7.395,30$ & 614 & 31,71 & 40,93 & 2,11 \\
\hline 2 & Karangampel & $6.251,30$ & 304,50 & & 20,30 & \\
\hline 3 & Juntiyuat & $5.361,00$ & 296,54 & & 19,77 & \\
\hline 4 & Balongan & $3.653,30$ & 440,69 & 73,35 & 29,38 & 4,89 \\
\hline 5 & Indramayu & $5.398,60$ & 370,25 & 56,32 & 24,68 & 3,75 \\
\hline 6 & Cantingi & $5.862,40$ & 132,45 & 219 & 8,83 & 14,60 \\
\hline 7 & Pasekan & $6.870,90$ & 375,27 & 120,75 & 25,02 & 8,05 \\
\hline 8 & Losarang & $13.787,40$ & 134,10 & 20,79 & 8,94 & 1,39 \\
\hline 9 & Kandanghaur & $8.582,20$ & 371,32 & 110,11 & 24,75 & 7,34 \\
\hline 11 & Sukra & $4.488,30$ & 742,16 & 15,49 & 49,48 & 1,03 \\
\hline 10 & Patrol & $4.333,00$ & 119,13 & 2,86 & 7,94 & 0,19 \\
\hline & Total & $71.983,70$ & 3900,41 & 650,29 & 23,64 & 4,81 \\
\hline
\end{tabular}

\subsection{Hasil Perhitungan Rasio Lahan}

Hasil perhitungan rasio lahan dihitung berdasarkan Persamaan 3. Tabel 4 memperlihatkan prediksi rasio lahan sawah dan penduduk tahun 2015 sedangkan Tabel 5 memperlihatkan prediksi rasio lahan sawah dan penduduk tahun 2025 . 
Tabel 4. Prediksi Rasio Lahan Sawah dan Penduduk Tahun 2015

\begin{tabular}{|c|c|c|c|c|c|c|}
\hline No & Kecamatan & $\begin{array}{c}\text { Luas } \\
\text { Lahan } \\
2015[\mathrm{Ha}]\end{array}$ & $\begin{array}{c}\text { Jumlah } \\
\text { Penduduk } \\
2015 \text { [Jiwa] }\end{array}$ & $\begin{array}{c}\text { Jumlah } \\
\text { Petani } \\
\text { [Jiwa) } * \text { ] }\end{array}$ & $\begin{array}{c}\text { Rasio } \\
\text { Lahan } \\
\text { Penduduk } \\
{[\text { Ha/Jiwa] }}\end{array}$ & $\begin{array}{c}\text { Rasio Lahan } \\
\text { Petani } \\
\text { [Ha/Petani] }\end{array}$ \\
\hline 1 & Krangkeng & 4043,45 & 69930,03 & 11.069 & 0,06 & 0,37 \\
\hline 2 & Karangampel & 3019,88 & 69335,32 & 5.117 & 0,04 & 0,59 \\
\hline 3 & Juntinyuat & 6233,09 & 90654,97 & 7.029 & 0,07 & 0,89 \\
\hline 4 & Balongan & 2300,49 & 43695,29 & 8.155 & 0,05 & 0,28 \\
\hline 5 & Indramayu & 2301,25 & 111551,01 & 5.051 & 0,02 & 0,46 \\
\hline 6 & Cantigi & 1062,80 & 25951,29 & 660 & 0,04 & 1,61 \\
\hline 7 & Pasekan & 2116,42 & 25232,42 & - & 0,08 & \\
\hline 8 & Losarang & 6168,84 & 61918,51 & 10.920 & 0,10 & 0,56 \\
\hline 9 & Kandanghaur & 6782,92 & 93360,64 & 10.214 & 0,07 & 0,66 \\
\hline 10 & Sukra & 6100,46 & 49294,68 & 11.374 & 0,12 & 0,54 \\
\hline \multirow[t]{3}{*}{11} & Patrol & 5055,18 & 58915,60 & - & 0,09 & \\
\hline & & 45184,78 & 699839,76 & 69589,00 & $\mathbf{0 , 0 7}$ & 0,66 \\
\hline & & & Jumlah & & \multicolumn{2}{|c|}{ Rata-rata } \\
\hline
\end{tabular}

Tabel 5. Prediksi Rasio Lahan Sawah dan Penduduk Tahun 2025

\begin{tabular}{llrrrrr}
\hline No & Kecamatan & $\begin{array}{c}\text { Luas } \\
\text { Lahan } \\
\mathbf{2 0 2 5}[\mathbf{H a}]\end{array}$ & $\begin{array}{c}\text { Jumlah } \\
\text { Penduduk } \\
\mathbf{2 0 2 5}[\mathbf{J i w a}]\end{array}$ & $\begin{array}{c}\text { Jumlah } \\
\text { Petani } \\
\text { [Jiwa) *] }\end{array}$ & $\begin{array}{c}\text { Rasio } \\
\text { Lahan } \\
\text { Penduduk } \\
\text { [Ha/Jiwa] }\end{array}$ & $\begin{array}{c}\text { Rasio Lahan } \\
\text { Petani } \\
\text { [Ha/Petani] }\end{array}$ \\
\hline 1 & Krangkeng & 3159,02 & 74156,44 & 11.069 & 0,04 & 0,29 \\
\hline 2 & Karangampel & 2470,98 & 70484,37 & 5.117 & 0,04 & 0,48 \\
\hline 3 & Juntinyuat & 5340,692 & 92228,93 & 7.029 & 0,06 & 0,76 \\
\hline 4 & Balongan & 1731,092 & 44481,69 & 8.155 & 0,04 & 0,21 \\
\hline 5 & Indramayu & 1782,82 & 113517,92 & 5.051 & 0,02 & 0,35 \\
\hline 6 & Cantigi & 851,3 & 26397,25 & 660 & 0,03 & 1,29 \\
\hline 7 & Pasekan & 1614,436 & 25648,74 & - & 0,06 & \\
\hline 8 & Losarang & 5401,14 & 62962,18 & 10.920 & 0,09 & 0,49 \\
\hline 9 & Kandanghaur & 5776,576 & 95057,95 & 10.214 & 0,06 & 0,57 \\
\hline 10 & Sukra & 5351,044 & 50163,98 & 11.374 & 0,11 & 0,47 \\
\hline 11 & Patrol & 3967,908 & 59992,32 & - & 0,07 & \\
\hline & & $\mathbf{3 7 4 4 7 , 0 0 8}$ & $\mathbf{7 1 5 0 9 1 , 7 8 3 6}$ & $\mathbf{6 9 5 8 9}$ & $\mathbf{0 , 0 5}$ & $\mathbf{0 , 5 5}$ \\
\hline & & Jumlah & & Rata-rata & \\
\hline
\end{tabular}

Hasil perhitungan pada Tabel 4 dan Tabel 5 tersebut memperlihatkan bahwa semakin besar laju abrasi mengakibatkan semakin kecilnya rasio lahan di tahun mendatang dan berkurangnya produktivitas dari lahan serta banyaknya petani yang akan kehilangan pekerjaan. Variabel yang paling dominan terhadap perubahan nilai rasio lahan pada 11 kecamatan Pesisir Indramayu adalah pertumbuhan penduduk. Tetapi, adanya fenomena abrasi dan sedimentasi ini mempercepat penurunan laju rasio lahan di 11 kecamatan pesisir Indramayu. Hal ini disebabkan karena abrasi mengakibatkan berukurangnya luas lahan di wilayah tersebut. 


\section{SIMPULAN}

Metode yang efektif dalam mengidentifikasi batas darat dan air untuk penentuan garis pantai dengan menggunakan citra satelit secara visual adalah dengan metode komposit RGB 4, 5, 7 dan Metode AGSO. Kedua metode ini memberikan kekontrasan yang jelas antara perairan dan daratan sehingga memudahkan dalam proses penentuan garis pantai yang nantinya digunakan untuk perhitungan luas abrasi dan sedimentasi. Luas abrasi di 11 Kecamatan Pesisir Indramayu dari tahun 1994 - 2009 sebesar 3900,41 Ha dengan laju abrasi rata-rata sebesar 23,64 Ha/ tahun dan Luas sedimentasi sebesar $650,29 \mathrm{Ha}$ dengan laju sedimentasi rata-rata sebesar 4,81 Ha/tahun. Terjadinya pengurangan lahan akibat abrasi mengakibatkan turunnya rasio lahan baik terhadap penduduk dan petani. Hasil perhitungan regresi terhadap rasio lahan penduduk untuk tahun 2015 sebesar $0,07 \mathrm{Ha} /$ jiwa dan menurun pada tahun 2025 menjadi 0,05 Ha/jiwa . Rasio lahan petani untuk tahun 2015 sebesar 0,66 $\mathrm{Ha} /$ petani dan menurun menjadi 0,55 Ha/petani di tahun 2025.

\section{DAFTAR PUSTAKA}

[1] Badan Pusat Statistik Kabupaten Indramayu. Indramayu dalam Angka Tahun 2008. Indramayu; 2008.

[2] Bappeda Kabupaten Indramayu. Peta Lokasi Abrasi di Kabupaten Indramayu. Indramayu; 2008.

[3] Dinas Perikanan Provinsi Jawa Barat. Rencana Zonasi Kawasan Pesisir dan Laut Kabupaten Indramayu. Bandung; 2007.

[4] Wisayantono, D., Windupranata, D., Hayatiningsih, I., Indra, T., Sianturi, D.R. Asosiasi Geografikal Abrasi Pantai terhadap Rasio Lahan- Petani di 11 Kecamatan Pesisir- Kabupaten Indramayu. Laporan Teknis Program Hibah Kompetitif Dikti. Bandung: Institut Teknologi Bandung (ITB); 2009.

[5] Windupranata, W., Wisayantono, D., Hayatiningsih, I., Prawira, H. Dampak Spasial dan Temporal Pengrusakan Wilayah Pesisir oleh Parameter-Paramater Oseanografi terhadap Kegiatan Ekonomi di Wilayah Pesisir Utara Jawa Barat. Laporan Kemajuan Program Hibah Kompetitif Dikti. Bandung: Institut Teknologi Bandung (ITB); 2009. 